\title{
A REFORMA DA LEI GERAL DE TELECOMUNICAÇÕES E SEUS CONSTITUINTES: RISCOS E OPORTUNIDADES PARA UNIVERSALIZAÇÃO DO ACESSO À INTERNET E INCLUSÃO DIGITAL NO BRASIL ${ }^{1}$
}

THE PROPOSED AMENDMENT TO THE GENERAL TELECOMMUNICATIONS ACT AND ITS CONSTITUENTS: RISKS AND OPPORTUNITIES FOR UNIVERSAL INTERNET ACCESS AND DIGITAL INCLUSION IN BRAZIL

\section{FABRICIO B PASQUOT POLIDO}

Professor Adjunto de Direito Internacional da Faculdade de Direito da Universidade Federal de Minas Gerais (UFMG). Professor do corpo permanente do Programa de Pós-Graduação em Direito da UFMG. Doutor em Direito Internacional pela Universidade de São Paulo e Mestrado pela Universitá degli Studi di Torino, Itália. Foi pesquisador visitante - nível Pós-Doutorado - junto ao Instituto Max-Planck de Direito Internacional Privado e Comparado de Hamburgo, Alemanha. É membro da Associação Americana de Direito Internacional Privado, do Comitê de Direito Internacional Privado e Propriedade Intelectual da International Law Association, Observatório Brasileiro de Direito Internacional Privado - Brazilian PIL Watch e do

\footnotetext{
1 O presente trabalho integra resultados do projeto de pesquisa "Estado e Mundialização: Fronteiras do Trabalho e Tecnologias", da linha "História, Poder e Liberdade", do Programa de Pós-Graduação em Direito da Universidade Federal de Minas Gerais, e derivou de frutíferas discussões promovidas nas reuniões de trabalho para elaboração do perfil brasileiro no Relatório 'Freedom on the Net 2018', e nos seminários avançados de pesquisa realizados em setembro de 2018 pela Escola de Estudos Internacionais da Universidade de Kent, em Bruxelas. Na oportunidade do Seminários de Bruxelas, os participantes discutiram temas correlatos em trabalhos do projeto colaborativo de investigação "Práticas de Inclusão, Direito e Regulação na União Europeia e na América Latina - IPP", coordenado pelo autor e pela Professora Toni Williams, da Universidade de Kent (2013-2018), selecionado para fundo de mobilidade e intercâmbio de pesquisa pela Academia Britânica. O autor agradece enormemente à CAPES pelo apoio parcial concedido durante a execução das pesquisas (Cód. Financeiro 001, Processo n. 88881.171915 / 2018-01 - Edital PVE 45-2017 - "Programa de Professor Visitante no Exterior").
} 
Conselho Científico do Instituto de Referência em Internet e Sociedade - IRIS. Advogado e consultor. E-mail: fpolido@ufmg.br.

\section{RESUMO}

O artigo sugere uma avaliação da proposta de reforma da Lei Geral de Telecomunicações de 1997 no Brasil, segundo o Projeto de Lei no 79/2016, atualmente em tramitação no Congresso Nacional, e sua compatibilidade com o Marco Civil da Internet e objetivos da agenda global digital. Dentre esses objetivos destacamse a universalização do acesso à internet por banda larga de qualidade e a afirmação do direito de acesso à internet como direito humano. Um balanço de efetividade da LGT e escrutínio dos interesses que movem a iniciativa reformadora em curso também se revelam necessários, especialmente em função dos imperativos de transparência e debate público, centrais aos processos democráticos, e da relação indissociável entre políticas de inclusão digital e de transformação digital no Brasil. Qualquer oportunidade de reforma da LGT igualmente exige uma abertura para integração normativa com o Marco Civil, conducente com a promoção de políticas industriais, tecnológicas e de inovação, aptas a apoiar o incremento das bases educacionais e científicas no país.

PALAVRAS-CHAVE: Lei Geral de Telecomunicações; Marco Civil da Internet; Agenda Global Digital; Universalização do acesso à internet; Direitos Humanos; Inclusão Digital.

\section{ABSTRACT}

The article suggests an evaluation of the current proposed amendment to Brazilian General Telecommunications Law of 1997 by the Bill No. 79/2016, currently pending for approval by the National Congress, and its compatibility with the 2014 'Marco Civil da Internet' and further objectives of the global digital agenda. These objectives include the universalization of Internet access and the affirmation of right to access to the internet as a human right. One should remark the relevance of both an effectiveness' 
evaluation of the 1997 Act and the scrutiny of current stakes and lobbies underlying the ongoing legislative initiative, especially in view of pivotal principles of democratic process, such as in transparency and public debate, the inseparable relationship between digital inclusion and digital transformation policies for Brazil. Any opportunity to amend BGTA equally requires the openness toward the normative interplay with Marco Civil da Internet, which may be supportive to the promotion of industrial, technological and innovation policies aimed at increasing of educational and scientific bases in the country.

KEYWORDS: General Telecommunications Act; Marco Civil da Internet; Global digital agenda; Universal Internet Access; Human Right; Digital inclusion.

\section{INTRODUÇÃO}

Em 2017 e em plena juventude no Brasil, a Lei Geral de Telecomunicações (Lei no 9.472/1997) completou 20 anos e poucos talvez tenham parado para refletir sobre as razões de um necessário balanço de efetividade a alcançar as dimensões variadas desse importante segmento, sobretudo em função das regras e princípios que estruturam a ordem econômica e social na Constituição da República. Esse balanço, mais do que oportuno, não se resume apenas a aspectos regulatórios, à expansão de infraestrutura no país, aos benefícios trazidos às distintas regiões brasileiras, em suas manifestas desigualdades socioeconômicas e falhas nas políticas de integração. Ao completar 20 anos, a LGT deve ser examinada, igualmente, à luz de uma série de temas caros aos princípios e regras do Marco Civil da Internet ${ }^{2}$, particularmente os que refletem a proteção de direitos de usuários, políticas de inclusão digital e próprio direito de acesso à internet como um direito fundamental, em linha com as resoluções das Nações Unidas e consensos do Fórum de Governança da Internet.

2 Lei no 12.965, de 23 de abril de 2014. 
Entre os predicados atribuídos à existência e vigência da LGT no Brasil, observam-se o estreito simbolismo da integração e da universalização dos sistemas de telefonia fixa e móvel em um país de dimensão continental, além da transformação radical do ambiente de competição envolvendo as empresas atuantes no segmento de tecnologias de informação e comunicação. Nesse sentido, destacaram-se algumas variantes incontestáveis associadas à LGT: a aceleração do regime das privatizações desde a segunda metade da década de 1990; a escalada da concentração econômica nos mercados relacionados e subsequente formação de estruturas oligopolísticas (SOUSA MELO e GUTIERREZ, 2002) e o fortalecimento de maciços lobbies do setor nas esferas dos três poderes - Executivo, Legislativo e Judiciário, com processos nada transparentes e democráticos (LEAL e HAJE, 2007, p.9).

Para quem quer que tenha testemunhado os primeiros anos de vida da Lei, foi possível acompanhá-la desde os tempos de sua maturação, entrada em vigor e aplicação - temas caros ao direito positivo - até a efervescência de debates econômicos, regulatórios e concorrenciais em torno das políticas publicas e desenvolvimento, proporcionados pela superestrutura normativa então nascente (FARACO, 2003; SALOMÃO FILHO, 2012).

No entanto, em sua fase adulta, para além da reforma atualmente pretendida pelo Congresso Nacional no Projeto de Lei N. 79/2016 (CÂMARA DOS DEPUTADOS, 2016), - na esteira de hesitações, deslizes e verdadeiro 'circo dos horrores'-, a LGT merece uma releitura em torno das forças imaginárias e narrativas, de premissas redistributivas da economia digital e da própria sociedade global do conhecimento.

A ideia de 'sociedade global do conhecimento', propositalmente distópica, sugere estágio subsequente àquele oferecido originalmente por CASTELLS (2000) para delimitar as expressões da denominada "sociedade da informação", ou variantes da "sociedade pós-industrial". Castells parte de dado paradigma - o da tecnologia da informação - para justificar como as relações entre redes, economia e a sociedade estão estruturadas. Nessa formulação, a Sociedade da Informação é dotada de algumas características funcionais, tais como: informação como matéria-prima; efeitos intrusivos das novas tecnologias sobre atividade humana, individual e coletiva; predominância da racionalidade de redes; flexibilidade e reversibilidade em 
processos; e crescente convergência de tecnologias". O termo "sociedade global do conhecimento", assim, envolveria a comunidade internacional de sujeitos e atores (partindo de incursões metodológicas próprias dos estudos jurídicos internacionais e transnacionais), orientada para processos, interações e relações inter-humanas e as respectivas reações relativamente às tendências de apropriação e de publicização dos bens tecnológicos, informacionais, culturais, científicos e inovadores (genericamente, "bens do conhecimento") e que podem estar submetidos a distintas formas de produção, disseminação, gerenciamento, exploração, distribuição e consumo (POLIDO, 2013, p.208).

No extremo, testar as resistências da própria LGT, como lei vigente e marco regulatório da infraestrutura de telecomunicações como a conhecemos, também é promover um espaço deliberado de irritações sistêmicas, de exposição e escrutínio públicos. Esse espaço de debates, para retomar uma provocação habermasiana, deve obrigatoriamente sair dos gabinetes parlamentares e executivos, dos tribunais e dos escritórios, e ressoar na esfera pública, sobretudo quanto às expectativas e interesses da sociedade e de promoção da cidadania. Isso porque os motivos hoje expostos para a reforma da Lei operam sobre a bases da própria sobrevivência e desenvolvimento do campo radical das tecnologias da informação e comunicação (TICs), do acesso à internet como direito fundamental, da liberdade de expressão, e da facilitação de tudo aquilo que a Lei Geral de Telecomunicações veio ideologicamente representar dentro da ordem econômica e social da Constituição. Não faria sentido, portanto, sustentar um processo legislativo 'modernizador', quando seus efeitos estruturantes ou constituintes prejudiquem outros regimes regulatórios, direitos e obrigações de largo contingente populacional no Brasil.

A universalização originária e arquitetada pela LGT não se resumiria a reforçar ou incrementar meios de comunicação para cidadãos no Brasil, mas antes propugnaria por decisões de políticas públicas orientadas para a gradual

\footnotetext{
${ }^{3} \mathrm{~A}$ convergência de tecnologias tem sido elemento central nos processos políticos e econômicos em torno da indústria de $\mathrm{Tl}$ e internet, passando pelas revoluções nos campos da microeletrônica, telecomunicações, optoeletrônica, informática, robótica, biotecnologia, nanotecnologia, genética e que hoje balizam o desenvolvimento de estruturas, dispositivos, produtos e serviços associados ao Big Data, Inteligência Artificial e Internet das Coisas.
} 
transformação dos serviços de telecomunicação no território nacional ${ }^{4}$. E eles seriam também indispensáveis para o funcionamento de uma sociedade democrática, na qual constituinte e legislador infraconstitucional pudessem contribuir para conformação de um espaço de mediação entre Estado regulador da atividade econômica e mercados funcionalizados por interesses de promoção da concorrência, proteção do consumidor, redução das disparidades regionais e inovação (Cf., por exemplo, Arts. 170, $219 \mathrm{CF} / 88)$. Da mesma forma, os debates públicos levantados pela LGT deveriam também ocorrer em função de outros valores, como a efetividade de normas constitucionais e internacionais suportando o Estado Democrático de Direito, a promoção de direitos humanos e da preservação da internet como representativa de amplo espaço transnacional das tecnologias e da informação (POLIDO, 2013, p.214).

O fato é que a LGT lançou bases e exigências de um autêntico regime público voltado para universalização das redes de telefonia fixa, expandida para regiões mais afastadas, nos rincões de um país preponderantemente subdesenvolvido. O propósito da Lei parece não ter sido acompanhado, nas décadas seguintes, do alargamento qualitativo e quantitativo da infraestrutura de telefonia móvel, de revisão de políticas tributárias regressivas ou de outras preocupações também prementes e necessárias, como considerações sobre a eficiência redistributiva por detrás do desenho regulatório adotado (COUTINHO, 2005, p. 149). Com regras menos rígidas e fundadas na dinâmica do mercado, por exemplo, as linhas de telefonia móvel celular receberam inicialmente alcance menor; posteriormente, com o incremento no número de assinantes, restou nítido o descompasso entre a forma de prestação, a estrutura dos preços e a qualidade em relação à estabilidade e alcance dos serviços contratados.

\footnotetext{
4 Destaco aqui, apenas a título explicativo, a concepção original proposta no Anteprojeto da LGT (ANATEL, 1996, p.18): "Com relação ao serviço universal, é importante fixar, inicialmente, o seu conceito. Como enfatizado anteriormente, o desenvolvimento do novo modelo institucional para as telecomunicações brasileiras é suportado num conjunto de objetivos que podem ser sintetizados em duas idéias principais: a competição na exploração dos serviços e a universalização do acesso aos serviços básicos. A idéia da universalização do acesso contempla duas situações genéricas: a) serviços de telecomunicações individuais, com níveis de qualidade aceitáveis, devem ser fornecidos, a tarifas comercialmente razoáveis, dentro de um prazo razoável, a qualquer pessoa ou organização que os requisitar; b) outras formas de acesso a serviços de telecomunicações devem ser fornecidas, em localizações geográficas convenientes, a tarifas acessíveis, àquelas pessoas que não tiverem condições econômicas de pagar tarifas comercialmente razoáveis por serviços individuais".
} 
Mas foi justamente durante o percurso de amadurecimento da LGT e de sua trajetória que a internet se consolidou no Brasil. E a consolidação da internet deu-se graças, e sobretudo, aos serviços de provimento de conexão. Hoje esses serviços estão, em larga medida, associados à própria expansão de banda larga, quer pelo serviço móvel pessoal, quer por aquele de banda larga fixa a alcançar residências, empresas, universidade e entidades governamentais. E ambos convivem com serviços de telefonia tradicionais ainda subsistentes e ofertados pelas grandes operadoras (PENA, ABDALLA JR., PEREIRA 2012, p.237).

Alguns eventos e números nos ajudam a corroborar a atualidade e necessidade de revisão do assunto aqui discutido, em direção ao balanço de efetividade da LGT e reforma para a universalizar o acesso à internet. Dados da Anatel relativos a 2017 demonstraram que $42 \%$ dos lares brasileiros já contam com acesso à internet por banda larga (ANATEL, 2018). Segundo Relatório do Comitê Gestor da Internet referente a 2016, 69\% dos brasileiros já haviam acessado a web (CGI, 2017). Dados relativos à expansão e à penetração da Internet no país evidenciam certas discrepâncias consideráveis: os índices são muito diferentes entre áreas urbana $(72 \%)$ e rural $(49 \%)$, entre as classes DE $(46 \%)$ e A $(96 \%)$ e entre grupos, a saber, usuários com ensino superior completo (98\%) e usuários com ensino fundamental (56\%)(CGI, 2017).

Igualmente, desde 2004, o acesso à internet é considerado direito humano pela Organização das Nações Unidas (ONU, 2016). No Brasil, Marco Civil da Internet de 2014 estabelece que a disciplina do uso da internet tem como objetivo a promoção do direito de acesso à internet a todos. Ele consagra um princípio de universalização, equilibrando-o com os interesses de acesso à informação e conhecimento, participação na vida cultural, da promoção da atividade inovadora e de difusão de novas tecnologias, da adesão de novos padrões de comunicação, acessibilidade e interoperabilidadel ${ }^{5}$.

\footnotetext{
${ }^{5}$ Cf Artigo $4^{\circ}$ do Marco Civil: "A disciplina do uso da internet no Brasil tem por objetivo a promoção: I do direito de acesso à internet a todos; I I - do acesso à informação, ao conhecimento e à participação na vida cultural e na condução dos assuntos públicos; III - da inovação e do fomento à ampla difusão de novas tecnologias e modelos de uso e acesso; e IV - da adesão a padrões tecnológicos abertos que permitam a comunicação, a acessibilidade e a interoperabilidade entre aplicações e bases de dados".
} 
O Marco Civil também reconhece obrigações e responsabilidades endereçadas a agentes econômicos da complexa cadeia informacional e da indústria da internet e tecnologias da informação, tais como provedores de acesso, de conteúdo e empresas de aplicação da internet ${ }^{6}$. Esse modelo de composição de interesses direitos, obrigações e responsabilidades- parece ter sido fundamental para estabelecer a fina sintonia entre as relações jurídicas em matéria civil e comercial e a esfera ou domínio público nos atores da internet. Códigos, leis ou regulamentos que conseguem êxito em alcançar essa matriz de interesses apresentam grandes chances de estabilização de expectativas jurídicas das partes, dentre as quais centradas na confiança, na segurança e na legalidade. Modernas instituições do direito privado, por exemplo, dependem da satisfação dessas expectativas como forma de medida de efetividade para a regulação normativa e desenvolvimento da codificação (AZEVEDO, 1999, p.3). E mais, é dessa maneira que códigos, leis e regulamentos alcançam um outro objetivo: de comunicar e informar a sociedade sobre as expectativas dos sujeitos e os papéis que eles desempenham dentro de um esquema dialógico com a constituição e direitos fundamentais (TEPEDINO, 2000).

A já adulta LGT nasceu com o propósito de estabelecer os marcos regulatórios para o setor de telecomunicações no Brasil, alcançando estruturas proprietárias antes concentradas na mão do Estado, e que passariam, sob a forma de alienação de ativos, de regimes de concessão de serviços e outros expedientes, para particulares (PENA, ABDALLA JR., PEREIRA 2012, p.239). No auge das privatizações durante a década de 1990 , vale destacar, essas foram as principais características da mudança brutal por que passou o setor no Brasil.

A LGT, todavia, ao desconhecer completamente o futuro Ihe seria reservado. não contemplou objetivo de regulamentação dos serviços de acesso à internet, que passaram a ser ofertados, no Brasil, mediante classificação de serviço de comunicação multimídia. Por contar com a regulação de estruturas de serviços essenciais de telecomunicações e do comportamento de agentes econômicos do setor, os efeitos secundários de suas regras afetariam enormemente a internet. A LGT, no fundo, tocaria a disponibilidade ou não da expansão de serviços de telefonia

${ }^{6}$ Cf. Arts. $3^{\circ}$, inciso VI e 9 e ss. 
elas associados e a própria a conectividade de usuários, lares e empresas por meio de serviços de banda larga fixa e móvel.

A partir desse divisor de águas, entre o nascimento e maturação da LGT e as demandas crescentes para universalização do acesso à internet por banda larga em quantidade e qualidade, é que são escancarados os grandes conflitos de interesses e de concepções sobre o que revela o movimento reformador da Lei em marcha e o que ele pode ou não oferecer. Esses conflitos, a meu ver, acenam para as rotas de colisão entre visões de mundo sobre a acessibilidade à informação, a construção do conhecimento e a concentração de poder econômico por parte de agentes que deixaram gradualmente de ter protagonismo em certo segmento da indústria e sua transição para outros mercados. É justamente o caso das operadoras de telefonia no Brasil e a batalha travada com as grandes corporações de internet. Da mesma forma, esses conflitos escancaram os riscos impostos ao uso socialmente relevante da internet, desde aspectos técnicos relativos à neutralidade de rede e à disponibilidade de infraestrutura de conexão até as questões intimamente ligadas à agenda global digital, especificamente inclusão digital e transformação digital e que tangenciam os eixos da governança da internet (DE NARDIS, 2013; KURBALIJA, 2016).

A reforma proposta para a LGT, hoje no esquadro no PL no 79/2016, traduzse em excelente exercício não apenas para compreensão das dinâmicas estruturais e concorrenciais não apenas das indústrias de $\mathrm{Tl}$ e de internet ou das mutações sofridas pelos mercados de telefonia e de internet. Como será analisado, ela revela as distintas ofensivas estabelecidas pelas empresas de telefonia fixa e celular e as empresas de internet e de tecnologias da informação para assegurar interesses na preponderância da oferta de internet e de conteúdos que possam integrar bens e serviços digitais no Brasil7. Mesmo reconhecendo existirem interesses legítimos quanto ao viés transformativo do modelo regulatório, ampliado para universalização

\footnotetext{
7 Não por acaso, são elas campeãs de reclamações em matéria regulatória e de defesa do consumidor, ao lado de operadoras de TV a cabo, bancos, operadoras de cartão de crédito, lojas de varejo e companhias aéreas no Brasil (PROCON, 2018). Ao contrário do que as matrizes liberais econômicas poderiam propor, são indicadores de demonstram a relação entre a necessidade de regulação maciça pelo Estado e o funcionamento dos mercados. Depois de quase 30 anos da Reforma do Estado, pelas lentes da Administração Pública e o movimento iniciado na década de 1990 durante o mandato do expresidente Fernando Henrique Cardoso, seria pecar pelos mesmos erros a insistência em modelo que abandone o escopo regulatório e a presença do Estado na regulação da atividade econômica, na geração de bem-estar e desenvolvimento e a proteção de interesses coletivos.
} 
do acesso à internet no país, subsistem preocupações sobre os rumos e rotas alternativas para a agenda digital, como no campo da inclusão e transformação digital.

Desse modo, parece relevante, à guisa de um trabalho de investigação preliminar, estabelecer algumas premissas de análise e que espelham as seguintes questões: (i) os limites entre a composição de aspectos técnicos e legais que inspiram os principais interesses apresentados na para reforma da LGT segundo o PL no $79 / 2016^{8}$ e os imperativos de transparência e debate público, centrais aos processos democráticos; (ii) a relação indissociável entre políticas de inclusão digital e de transformação digital no Brasil, dependente de tomada de posição e de política pública a considerar a universalização do acesso à internet como objetivo a ser ampliado por serviços de provimento de acesso por banda larga; (iii) oportunidades de reforma da LGT consentâneas com a a abertura para integração normativa com o Marco Civil, sobretudo para indução de políticas industriais, tecnológicas e de inovação, aptas a apoiar o incremento das bases educacionais e científicas no país.

\section{REFORMA DA LGT PELO PROJETO DE LEI 79/2016 E DEBATE SOBRE UNIVERSALIZAÇÃO DA INTERNET}

O Projeto de Lei da Câmara n. 79/2016, originalmente apresentado pelo Deputado Daniel Vilela (MDB-GO), encontra-se pendente para aprovação no Senado Federal. Em larga medida, ele resume o principal design legislativo esperado para a reforma da LGT no Brasil. Cercada de inúmeras polêmicas, o PL busca alterar radicalmente o regime de exploração de atividades econômicas no segmento das telecomunicações, ampliando as hipóteses de autorização, em substituição ao vigente regime de concessões. O Projeto, inclusive, propõe regra para atribuir competência para a Anatel apreciar pedido de empresas concessionárias interessadas, para

\footnotetext{
8 Dentre vários, a problemáticas da reversibilidade de bens de titularidade da União em favor de agentes em oligopólio, como as grandes operadoras de telefonia, e da ausência de regras expressas (positivas, portanto) no Projeto de Lei em discussão, que associem a exploração de serviços de provimento de acesso à internet por banda larga à categoria de serviços de interesse público, passíveis de universalização e/ou de precisos compromissos de investimentos no setor. Trata-se justamente do cerne da crítica a ser levantada, em coro com as principais posições contra a presente configuração do texto reformador (ex vi Arts. 62, 63)
} 
conversão do regime de concessão para regime de autorização, sob a condição genérica de "manutenção da prestação do serviço adaptado e compromisso de cessão de capacidade que possibilite essa manutenção, nas áreas sem competição adequada, nos termos da regulamentação da Agência".

Basicamente, as empresas de telefonia defenderam a necessidade de aprovação da medida como forma de reduzir obrigações vigentes e estimular investimentos no setor, abrindo espaço para ampliar o alcance das redes e, consequentemente, o acesso à internet. Organizações da sociedade civil e de defesa do consumidor, por sua vez, apontaram falhas consideradas graves na proposta de regulamentação da matéria pela LGT reformada. Entre os exemplos mais problemáticos estaria a entrega de mais de $R \$ 70$ bilhões em infraestrutura atualmente pertencente à União às operadoras ${ }^{9} \mathrm{e}$ a supressão, da LGT, de obrigações consideradas centrais para a oferta de serviços essenciais de telecomunicações, e que poderiam também ser aplicadas ao segmento da provisão de serviços de banda larga.

Segundo informações levadas às audiências sobre o Projeto de Lei ํo $79 / 2016$, os bens reversíveis totalizariam aproximadamente $R \$ 100$ bilhões, valor que ainda permanece sob controvérsia e polêmica, sobretudo pela discussão sobre a soma patrimonial efetiva das redes hoje utilizadas diretamente pelas operadoras concessionárias $^{10}$. A Anatel, por sua vez, sustentou que a avaliação desses bens

9 Cf. especificamente nota publicada em <http://agenciabrasil.ebc.com.br/politica/noticia/201805/senado-especialistas-empresas-e-governo-debatem-lei-geral-das-teles $>$. Acesso: 30 de dezembro de 2018. Ela reflete a sucessão dos debates travados nas audiências públicas realizadas pelo Congresso e que resultaram na intervenção das organizações da sociedade civil e especialistas.

${ }^{10} \mathrm{~A}$ esse respeito, ver entrevista dada pelo então presidente da Anatel, Juarez Quadros, para matéria do Teletime ("Para Anatel, valor dos bens reversíveis só podem ser calculados após sanção do PLC 79/2016 (SILVEIRA, 2018)

Destaco, a esse propósito, que bens reversíveis compõem categoria de bens vinculada ao instituto da concessão de serviço público, como contrato típico do direito administrativo. Em linha com o conceito apresentado por SUNDFELD e ARRUDA CÂMARA (2016, p.150), pela concessão, "o poder público delega a particular o direito de prestar o serviço e de explorá-lo economicamente. Mas a atividade não deixa de ser de titularidade pública: findo o prazo, ou extinto precocemente o contrato, a prestação do serviço retorna ao titular. Só que a retomada, para ocorrer na prática, depende de soluções que evitem a descontinuidade do serviço quando da substituição do prestador". E prosseguem: "(....) A transferência dos bens e direitos vinculados à concessão - a reversão - tornou-se uma das medidas mais comuns. Nas concessões tradicionais, ela normalmente se justificava quanto aos bens necessários e insubstituíveis, a partir da crença de que, sem a propriedade deles, o estado não teria como, após a retomada, exercer de fato seu poder de prestar o serviço. Por isso é que esses bens não permaneciam com o particular; por isso os contratos impunham sua reversão". 
somente poderia ser realizada após a promulgação da Lei reformadora, com a contratação de consultorias (AGÊNCIA BRASIL, 2018).

Ao acompanhar a discussão técnica e de fundo transposta para o processo legislativo em curso, as organizações da sociedade civil na área da proteção do consumidor têm se insurgido frontalmente contra o modelo pleiteado pelo lobby das operadoras. Esse modelo propugna pela predominância de um regime de autorizações em detrimento de concessões. Desde 2011, a Proteste, por exemplo, tem atuado para exigir mais transparência nos contratos vigentes com as empresas de telecomunicações. Em janeiro de 2018, a Organização logrou êxito em manter a decisão da Justiça Federal determinando a obrigação da ANATEL de incluir inventário de bens reversíveis nos contratos de concessão para serviços de telefonia fixa comutada, celebrados com a Telefônica, Oi e Embratel, ainda em 1998, e prorrogados em 2005 até dezembro de $2025^{11}$.

Entre os bens reversíveis encontram-se imóveis, equipamentos e as redes de transmissão, interconexão e acesso para prestação dos serviços de telecomunicações e de acesso a Internet (ANATEL, 2015). Não se trata, portanto, de discussão meramente ilusiva, técnica ou legalista do direito administrativo brasileiro. Segundo o desenho legislativo proposto, bens reversíveis, hoje sob concessão às operadoras atuantes no segmento de Serviço de Telefonia Fixa Comutada, poderão ser por elas retidos, como resultado da adoção e execução de instrumentos de autorização previstos pela nova versão da LGT. Esses bens, de titularidade da União, compõem a infraestrutura fundamental de telecomunicações e da internet no Brasil.

A discussão é estratégica, portanto, para o desenvolvimento das diversas ordens que fundamentam a Constituição da República, em particular a social e econômica. A rota de mutação legislativa proposta poderia retirar o conteúdo materialmente constitucional da LGT e de outras leis infraconstitucionais, como o próprio Marco Civil da Internet, dentro daquilo que o Marco Civil prevê relativamente à universalização do acesso à internet.

${ }^{11}$ Cf. TRF 1a Região, Embargos de Declaração na Apelação Cível No. 0029346-30.2011.4.01.3400. Rel. Des.:Carlos Moreira Alves. Decisão de $1^{\underline{0}}$ de fevereiro de 2018 . Disponível em: <http://teletime.com.br/wp-content/uploads/2018/02/Bens-Reversiveis-EmbDeclrcao-1-fev-2018.pdf>. Acesso: 30 de dezembro de 2018. 
Justamente nesse momento, entrarão em cena potenciais discussões de direito administrativo no esquema regulatório e seus clientes habituais, sobretudo quanto à eventual especificidade do setor de telecomunicações, e que aqui não poderiam ser detalhadas ${ }^{12}$. Duas passagens do Projeto de Lei $n^{0}$ 79/2016, contudo, parecem suscitar preocupações sensíveis e que estão na berlinda das disputas de interesses entre os 'stakeholders' no processo legislativo reformador sobre que rumo deve tomar a universalização do acesso à Internet.

A aprovação da reforma, da maneira como resistiu o texto do Projeto de Lei original da Câmara, altera profundamente o setor de telecomunicações, ao menos segundo o aspecto da fragmentação regulatória e dos efeitos sobre o regime de bens da União existentes e que compõe a estrutura de telecomunicações e provimento de acesso a banda larga. Do ponto de vista das categorias contratuais, o texto vigente do PL no 79/2016 beneficiaria operadoras com adoção de instrumentos jurídicos de adaptação da outorga de concessão para modalidade de autorização, submetidos à discricionariedade da ANATEL, com seus inevitáveis riscos regulatórios e capturas.

Primeiramente, as fórmulas desenhadas no Projeto potencializam disputas em torno da definição do "valor econômico" relativo à adaptação dos contratos de concessão vigentes, celebrados entre a União e as operadoras, nos termos do Art.21, inciso XI, da Constituição e da LGT. Segundo a proposta trazida pelo Projeto de Lei na redação a ser dada ao Art.68-B da LGT, o valor econômico implicado na adaptação de regime seria determinado pela diferença entre os valores esperados para a exploração do serviço no regime de autorização e para exploração em concessão. Ainda segundo o Art.68-B,§ 20, o "valor econômico" da adaptação será suscetível de reversão em "compromissos de investimento"', conforme prioridades estabelecidas pelo Executivo. Os compromissos de investimentos seriam definidos também dentro do escopo dos instrumentos de autorização, adaptados dos contratos de concessão

\footnotetext{
${ }^{12}$ Criticamente, ver artigo de SUNDFELD e ARRUDA CÂMARA (2016, p.150) que, à primeira vista, manifestam-se sobre a discricionariedade ampla do órgão regulador, no caso Anatel, para decidir sobre a reversibilidade, segundo 'solução flexível' da concessão ("A escolha do setor de telecomunicações para demonstrar a existência da pluralidade de regimes de reversão não foi aleatória. A regulação do setor, embora preveja esse instrumento (à diferença de outros setores, em que, devido à natureza dos serviços, a concessão não o contempla), tem solução flexível, com competência ampla para, ao final da concessão, o órgão regulador fixar, segundo as contingências do momento, o nível de comprometimento do concedente com os bens atrelados à prestação do serviço").
} 


\title{
vigentes, nos termos do Art. 68-A do Projeto. Os rascunhos dos textos dois dispositivos merecem ser aqui transcritos:
}

\begin{abstract}
Art. 68-A. A Agência poderá autorizar, mediante solicitação da concessionária, a adaptação do instrumento de concessão para autorização, condicionada à observância dos seguintes requisitos: I - manutenção da prestação do serviço adaptado e compromisso de cessão de capacidade que possibilite essa manutenção, nas áreas sem competição adequada, nos termos da regulamentação da Agência; II - assunção, pela requerente, de compromissos de investimento, conforme o art. 68-B; III - apresentação, pela requerente, de garantia que assegure o fiel cumprimento das obrigações previstas nos incisos I e II; e IV - adaptação das outorgas para prestação de serviços de telecomunicações e respectivas autorizações de uso de radiofrequências detidas pelo grupo empresarial da concessionária em termo único de serviços. $\S 10 \mathrm{Na}$ prestação prevista no inciso I, deverão ser mantidas as ofertas comerciais do serviço adaptado existentes à época da aprovação da adaptação nas áreas sem competição adequada, nos termos da regulamentação da Agência. § 20 Ressalvadas as obrigações previstas nos incisos I e II, o processo de adaptação previsto no inciso IV dar-se-á de forma não onerosa, mantidos os prazos remanescentes das autorizações de uso de radiofrequências. $\S 30$ As garantias previstas no inciso III deverão possibilitar a sua execução por terceiro beneficiado, de forma a assegurar o cumprimento das obrigações associadas às garantias. $\S 400$ contrato de concessão deverá ser alterado para fixar a possibilidade de adaptação prevista no caput deste artigo. § 50 Após a adaptação prevista no caput, poderá ser autorizada a transferência do termo previsto no inciso IV, no todo ou em parte, conforme regulamentação da Agência Nacional de Telecomunicações - ANATEL, desde que preservada a prestação do serviço].
\end{abstract}

[Art. 68-B. O valor econômico associado à adaptação do instrumento de concessão para autorização prevista no art. 68-A será determinado pela Agência, com indicação da metodologia e dos critérios de valoração.§ 100 valor econômico referido no caput deste artigo será a diferença entre o valor esperado a partir da exploração do serviço adaptado em regime de autorização e o valor esperado da exploração desse serviço em regime de concessão, calculados a partir da adaptação. § $20 \mathrm{O}$ valor econômico referido no caput deste artigo será revertido em compromissos de investimento, priorizados conforme diretrizes do Poder Executivo. § 30 Os compromissos de investimento priorizarão a implantação de infraestrutura de rede de alta capacidade de comunicação de dados em áreas sem competição adequada e a redução das desigualdades, nos termos da regulamentação da Agência. $\S 40$ Os compromissos de investimento mencionados neste artigo deverão integrar o termo de autorização de prestação de serviços previsto no inciso IV do art. 68-A. § 50 Os compromissos de investimento deverão incorporar a oferta subsidiada de tecnologias assistivas para acessibilidade de pessoas com deficiência, seja às redes de alta capacidade de comunicação de dados, seja aos planos de consumo nos serviços de comunicações para usuários com deficiência, nos termos da regulamentação da Agência].

Em segundo lugar, observa-se o potencial efeito casado entre o Art. 68-A e e

Art.68-B, dispositivos estratégicos segundo o desenho legislativo do PL nº 79/2016. 
Tanto a engenharia legal como a captura regulatória presentes no texto da Lei favorecem o resultado questionado no percurso legislativo, vale dizer, que a infraestrutura utilizada pelas operadoras concessionárias, desde a década de 1990, acabe retida pelas empresas e não retorne para a União (entidade concedente). Dependendo do arranjo jurídico estabelecido nos termos do Art.68-A objetivado, esses bens poderão simplesmente permanecer com Telefônica, Oi e Embratel, como resultado de uma forma de compensação econômica pela assunção dos "compromissos de investimento", após a reforma da LGT (ANASTACIO, SANTARÉM e ZANATTA, 2016) ${ }^{13}$.

A par da confusão regulatória de praxe e o foco deliberado nas questões transitórias entre os regimes de concessão e de autorização favorecendo as operadoras de telefonia, ficam descobertas, pela iniciativa legislativa, as principais demandas originadas pela expansão da internet no Brasil. Em nenhuma passagem do PL no 79/2016, por exemplo, há referência sobre a universalização dos serviços de provimento de acesso e expansão da banda larga propriamente considerada ${ }^{14}$.

$\mathrm{Na}$ visão das empresas de telefonia, predominante para a 'encomenda legislativa' por detrás do Projeto de Lei, parecem ser justamente as obrigações de universalização e as antigas metas de expansão da rede de telefonia fixa as responsáveis pela criação de 'insegurança jurídicas' e alegados prejuízos para o setor, decorrentes do regime de concessões.

Ao se esmiuçar o processo legislativo em marcha, as justificativas do texto do Projeto de Lei da Câmara inicial - PLC 3.435/2015 ${ }^{15}$ demonstram muito bem a racionalidade que inspira as demandas protecionistas da lei reformadora: são abertamente favoráveis a uma espécie de encilhamento ou blindagem do setor e são

\footnotetext{
13 Em linha com o §3o do Art. 68-B, ditos compromissos priorizam a implantação de "infraestrutura de rede de alta capacidade de comunicação de dados em áreas sem competição adequada e a redução das desigualdades"

${ }^{14}$ O debate procedimental e de fundo, no direito administrativo, pode ofuscar os efeitos sobre o que é essencial no pleito público formulado, de que é necessário assegurar a prestação de um serviço de interesse público vertido na universalização do acesso à internet por banda larga. A esse respeito, criticamente, ver teor do Parecer Técnico N. 159/2017/ATCOE/SEAP, da Procuradoria Geral da República, de 24 de fevereiro de 2017, disponível em <htto://teletime.com.br/wpcontent/uploads/2017/03/Parecer_MPF_plc79.pdf>.

15 Texto integral do PLC 3.435/2015 e pareceres das Comissões podem ser consultados em em <http://www.camara.gov.br/proposicoesWeb/fichadetramitacao?idProposicao=2025543> Último acesso em 30 de dezembro de 2018.
} 
contra a concorrência travada por agentes atuantes em mercados da economia digital, quer as grandes empresas de internet, quer as nascentes e pequenas e médias empresas, atuantes nos segmentos de serviços de provimento de acesso, de aplicações de internet e tecnologias da informação.

A reforma pretendida para a LGT brasileira também lança dúvidas quanto ao destino dos serviços de acesso à internet, que podem ser submetidos apenas para exploração sob regime privado, sem compromissos ou metas de universalização. $O$ PL nº 79/2016 utiliza a fórmula draconiana para minimizar qualquer obrigação legal de universalização para internet, a saber, "modalidades de serviço de interesse coletivo que, mesmo sendo essenciais, não estejam (sic) sujeitas a deveres de universalização"16.

Não se pode visualizar, portanto, em que medida a exploração essencialmente em regime privado teria condições de criar efetiva competição para "modalidades de serviço de interesse coletivo" também essenciais, como seriam serviços de internet, e que a reforma não contempla. Para a comunidade de interessados no reconhecimento do direito de acesso à internet como direito fundamental, em linha com resoluções da Assembleia Geral e e Conselho de Direitos Humanos das Nações Unidas (POLIDO, 2018, p. 58) e no enquadramento legal dos serviços de acesso como serviços passíveis de universalização dentro do novel quadro normativo estabelecido pelo Marco Civil da Internet, as expectativas políticas de reforma normativa certamente restaram frustradas.

Ainda seria possível voltar a um argumento extremamente delicado, mas factível no caso da necessária e tardia demanda por universalização da internet no Brasil. Apesar dos avanços observados quanto à penetração da internet em lares, da incidência crescente do uso civil, comercial e governamental, a qualidade do acesso por banda larga fixa e móvel ainda é precária no país. A grade de comparação pode ser dada em função da capacidade da indústria, contingente de usuários e acessibilidade a mercados digitais, como em países da Europa, Estados Unidos e países emergentes (FREEDOM HOUSE, 2018). Estudos no Brasil têm se concentrado

\footnotetext{
16 Transcreve-se do PL n. 79/2016 o texto do dispositivo: "O § 10 do art. 65 da Lei no 9.472, de 16 de julho de 1997, passa a vigorar com a seguinte redação: "Art. 65. § 10 Poderão ser deixadas à exploração apenas em regime privado as modalidades de serviço de interesse coletivo que, mesmo sendo essenciais, não estejam sujeitas a deveres de universalização".
} 
extensivamente nas variáveis de análise por instalação de redes, expansão de banda larga, degradação de velocidade e qualidade de tráfego por regiões, sem estabelecer critérios quantitativos, qualitativos e de preços comparados a experiências em outros países e que permitam confrontar a situação instalada e alcance dos usos de internet no Brasil (CETIC, 2018).

Faltam entre nós dados e estudos que possam demonstrar o que tem sido óbvio e frequente. Após 20 anos de vigência da LGT e lições já aprendidas com a "Reforma do Estado" da década de 1990, intensificam-se as absurdas falhas regulatórias dos setores envolvidos, em matéria econômica, concorrencial e proteção do consumidor, assim como os elevados preços praticados no mercado brasileiro. Empresas que hoje se encontram em posse direta das redes de telefonia de titularidade da União e suas estruturas essenciais retornam serviços de provimento de acesso de qualidade manifestamente inferior a qualquer outro padrão de qualidade aceitável entre países do G20, conforme estatísticas gerais da União Internacional das Telecomunicações. Inferior, portanto, a qualquer outro país com grupos populacionais distintos e de comparáveis padrão aquisitivo e custo médio por grupo populacional ao Brasil. Dito de outra forma: entre brasileiras e brasileiros, paga-se muito caro pela internet, recebe-se muito pouco e o pouco que é recebido é de péssima qualidade.

\section{CAMINHOS TORTUOSOS DA REFORMA DA LGT NO CONGRESSO E CENÁRIOS ALTERNATIVOS}

No Senado Federal, o PLC 79/2016 foi aprovado em caráter terminativo em várias comissões, sem passar, contudo, pela votação em plenário. Contra a decisão da Presidência da Casa, de remeter o projeto diretamente à sanção presidencial, em potencial violação ao Art.58, $\S 2^{\circ}$, I da Constituição da República, grupo de senadores impetrou mandado de segurança no Supremo Tribunal Federal ${ }^{17}$. Em sua decisão liminar, o Ministro Alexandre Moraes, determinou a imediata análise dos recursos

17 Cf. Mandado de Segurança no 34562, decisão monocrática de 9 de outubro de 2017. 
apresentados ao projeto e a submissão da proposta legislativa à Comissão de Ciência, Tecnologia, Inovação, Comunicação e Informática ${ }^{18}$

Desde maio de 2018, a tramitação do PL n. 79/2016 encontra-se sem andamento na CCT. Em audiência pública promovida pela Comissão, foram reveladas as significativas divergências entre governo, empresas e especialistas, a evidenciar os entraves políticos, ideológicos e de interesses em torno do modelo que deve ser adotado para o futuro da LGT e do setor no Brasil (AGÊNCIA BRASIL, 2018). Cenários alternativos, contudo, parecem não ser tão facilmente descortinados. Há quem advogue uma espécie de força-tarefa para emendar o Projeto, com a inclusão de regra estabelecendo que a infraestrutura de tráfego de internet seja explorada em regime público (submetida, portanto, a metas de universalização, controle de preços e outras obrigações), garantindo formas diversas de oferta do serviço de acesso aos cidadãos.

Vinte anos após a apresentação da "Exposição de Motivos" do Anteprojeto da LGT em 1996, encaminhado pelo então Ministro Sérgio Motta, do extinto Ministério das Comunicações (hoje renomeado como "Ministério da Ciência, Tecnologia, Inovações e Comunicações") (ANATEL, 1996) ${ }^{19}$, algumas questões devem ser formuladas para o adequado sequenciamento do debate público de revisão da Lei pelo Congresso:

(I) Como aproveitar as oportunidades de reforma da LGT para modernização do quadro regulatório para as telecomunicações, incluindo as comunicações social e digital? (II) Em que medida a LGT reformada pode alcançar, em seu âmbito material de aplicação, serviços de utilidade essenciais nesses segmentos? (III) Como a LGT reformulada pode espelhar a incorporação de padrões normativos, princípios que têm sido adotados no direito internacional, especial direito internacional dos direitos humanos, reconhecendo o direito de acesso à internet e direito à informação online como direitos fundamentais? (IV) Como compatibilizar e tornar consistentes as abordagens propostas da reforma da LGT com a base legal do Marco Civil Internet de 2014, e seus objetivos de política normativa, que reconhecem, dentre vários, o "direito de acesso à internet" para todos como objetivo a ser promovido (Art.4)?

\footnotetext{
18 Ver status do PL 79/2016. Até o fechamento do presente artigo, a matéria encontrava-se sob designação de um relator na Comissão de Ciência, Tecnologia, Inovação, Comunicação e Informática do Senado.

${ }_{19}$ Recordo que o Projeto originário resultou de um concerto entre distintos atores, como o Ministério das Comunicações, consultores nacionais e internacionais, a partir dos arranjos estabelecidos entre a ABC - Agência Brasileira de Cooperação, do Ministério das Relações Exteriores, a UIT - União Internacional de Telecomunicações, organismo especializado da Organização das Nações Unidas.
} 
Se houver alguma forma de composição de interesses entre os parlamentares, por exemplo, sobre a mudança de abordagem do modelo hoje vigente, de abandono da supremacia da telefonia fixa e sua substituição pelos serviços de banda larga, então seria justamente o momento de virada do objetivo de política normativa. Haveria espaço para postular-se para que a proposição em torno do acesso à Internet como "serviço de interesse coletivo" seja reverberada com maior contundência, como têm feito especialistas e a sociedade civil organizada.

A própria redação vigente do Art. 62, a meu ver, criou um cisma de política normativa que anima vetustas classificações do direito administrativo brasileiro, ainda repetidas pelos cultores, o que poderia facilitar a barganha de modelos entre os regimes de concessão e autorização e favorecer poucos agentes, que já operam em oligopólio no Brasil, como as empresas de telefonia. A reforma esboçada do dispositivo leva à resultado equivocado, ambíguo, para a projeção da norma alcançando o objetivo regulador sobre o setor das telecomunicações. Isso porque, como observado, a distinta classificação dos serviços - serviços de interesse coletivo vs. serviços de interesse restrito- será ditada pela generalidade discricionária do poder regulamentar (“abrangência dos interesses a que atendem”) (art. 62).

A partir daqui já seria fácil sentir - porém difícil de explicar - que o alegado anacronismo da LGT na era digital não esteja exatamente nas fórmulas dogmáticas da distinção entre serviços públicos e infraestrutura, temas tão caros para a hoje maltratada Constituição econômica brasileira, ou para os juristas e tecnocratas que operam nos escombros da memória legislativa e plutocrática da Ditadura Militar no Brasil (1964-1985), ao facilitar o intercâmbio de interesses e favores nos balcões e almoxarifados governamentais.

O anacronismo da LGT expõe, antes, a resistência corporativa das poucas grandes empresas hoje alcançadas pelo texto normativo, atuantes em oligopólio, e reverbera as pressões constantes exercidas sobre os Executivo e Legislativo, em seus gabinetes, almoxarifados e instâncias cartoriais, entre lobbies e descompromissos, para estrangular o segmento mais amplo das comunicações sociais e a vibrante economia digital. Até na criminalização dos usos da internet e imposição de travas à liberdade de expressão, sob o pretexto de extirpar as "fake news" das redes e plataformas sociais, esses lobbies já transitaram (IRIS, 2018). Flertam com o 
improvável, com perigoso, naquilo que o Brasil tem representado de retrocesso, de paternalismo e de subversão do modo de produção capitalista. Entre esses e tantos segmentos, empresas e investidores ameaçam abandonar o país imediatamente ao sentirem-se órfãos do Estado, sem subvenções, sem auxílios, sem imunidades e isenções tributárias.

Pois bem. Do luxo e do aparentemente supérfluo, como ocorria no final década de 1990, ao essencial na atualidade, a internet superou a estrutura monolítica e analógica da telefonia fixa. Deu vida ao protocolo de voz e alavancou a telefonia móvel celular, em seus pacotes de dados, como temos testemunhado. Ela demonstra, enfim, a transformação radical das estruturas vivas e artificiais das comunicações.

Segundo a última estatística analisada pelo Centro de Estudos sobre as Tecnologias da Informação e da Comunicação - CETIC, a incidência do uso da banda larga fixa manteve-se estável nos últimos 3 anos analisados, sendo ela a modalidade de conexão utilizada por cerca de 26 milhões de residências, com enorme disparidade entre as áreas urbana $(25,2 \mathrm{mi})$ e rural $(1,6 \mathrm{mi})$ no país (CGI 2018). Ainda segundo a pesquisa, o acesso à Internet por banda larga móvel (por modem e serviços 3G e 4G) tem se destacado expressivamente. Ela representa a principal forma de conexão para um quarto dos domicílios brasileiros com acesso à Internet na área urbana, presente em 9,4 milhões dos lares. Certas disparidades regionais seguem em redução em relação ao uso da banda larga móvel, com crescimento entre classes sociais menos favorecidas e em regiões que tradicionalmente apresentam conectividade por banda fixa mais restrita, como são os casos da região Norte, Centro Oeste e das áreas rurais (CGI 2018).

Os números coligidos pelo CETIC demonstram ao menos dois aspectos relevantes que têm sido, inclusive, identificados nos documentos e estatísticas revisitadas por organizações internacionais intergovernamentais e não governamentais (ITU, 2018; FREEDOM HOUSE, 2018). Eles reforçam a existência das profundas desigualdades ainda persistentes no Brasil em termos de acesso à internet (qualidade de conexão, alcance regional, perfil de classes sociais) e que são reflexo da perversa realidade socioeconômica do país, além do abismo entre regiões.

Evidentemente as regiões mais desfavorecidas merecem ser alcançadas e atendidas por um objetivo de universalização da internet, que poderia - e deve- ser- 
estabelecido na oportunidade de reforma da LGT. Contrariamente a essa intuitiva recomendação, no entanto, a discussão no Congresso Nacional volta-se para os lobbies das operadoras, na promessa de barganhas em torno dos bens reversíveis e de compromissos de investimentos em serviços públicos tecnologicamente ultrapassados.

Alguns argumentos reunidos pelo antigo Ministério das Comunicações em 2016, em seu diagnóstico de realização da consulta pública para a reforma da LGT, ecoavam razões plausíveis para suportar marcos legais de transformação dos serviços de telefonia e de integração dos serviços de comunicação social. A estagnação da telefonia fixa parece depender menos de desinteresse das operadoras de telecomunicações que permanecem em oligopólio no setor. Trata-se, antes, do esgotamento de modelo e superação de tecnologias de comunicação e informação em escala global.

A demanda por acesso à Internet no Brasil, por seu turno, experimenta contínuo caráter reprimido, sobretudo porque distintas áreas geográficas do país tendem a reunir condições de abastecimento precário, frágil, tanto em relação ao número de domicílios atendidos como velocidade e qualidade de conexão (CGI, 2018). É possível observar que a expansão do serviço de internet não poderia ser feita apenas com base em número de domicílios atendidos, mas antes em qualidade de acesso e preço ao usuário final, de modo a aproximar o Brasil aos indicadores da UIT e da OCDE.

Por outro lado, a reforma da LGT, ao lançar mais garantias às operadoras convencionais, e menos contrapartidas legais (a exemplo do que seriam obrigações de investimento traduzidas em universalização da internet pelo provimento de acesso em qualidade e em níveis diferenciais por região atendida), não resolverá os dilemas de modernização das plataformas e infraestrutura de ICT. Por isso mesmo, a demanda postulada, política e juridicamente, pela sociedade civil e especialistas, quanto à necessidade de alteração do modelo viciado das concessões do regime de STFC, é consistente com o movimento feito no plano internacional. De um lado, ela pressiona pela construção de infraestrutura de apoio à oferta de banda larga; de outro, acena para a necessidade de monitoramento e avaliação dos efeitos reais de novas 
tecnologias de comunicação e informação sobre o setor mais amplo de telecomunicações e como ele se especializa e dinamiza na economia digital.

O que garantiria, contudo, que gigantes do setor de telefonia terão incentivos para participar contestando o também elevado poder de mercado de outras de empresas de internet e TI que hoje estão na cadeia dos produtos e serviços digitais, como Google, Microsoft, Apple, Facebook? E como assegurar que mesmo passando a atuar maciçamente na indústria de internet as operadoras não logrem êxito em alcançar retrocesso na regulamentação do Marco Civil, em especial no tocante as áreas sob constante ataque no Brasil, como o risco de ruptura da neutralidade de rede e a imposição de franquias de tráfego?

Como observado no excelente texto de posição do Instituto Brasileiro de Defesa do Consumidor e Instituto Beta, de julho de 2016, apesar de as justificativas da proposta legislativa originária (PLC n. 3.453/2015) mencionarem, como foco central da discussão, políticas públicas de expansão da banda larga, necessárias para a infraestrutura do acesso à internet no Brasil, o projeto não resolverá dilemas que vão mais além de querelas regulatórias e bases práticas do direito administrativo econômico (ANASTACIO, SANTARÉM e ZANATTA, 2016) ${ }^{20}$.

Ao contrário, ele apenas revela as grandes assimetrias hoje existentes em termos de proteção de consumidor e políticas concorrenciais na área, como mencionado anteriormente. Da mesma forma, na opinião defendida pelas organizações, haveria "necessidade de garantir o acesso universal à Internet por meio de mecanismos de governança democráticos e pluriparticipativos". Isso pressupõe a continuidade de um processo negociador e de formulação de políticas públicas a partir de injunções no Congresso Nacional, nessa fase especificamente no Senado Federal.

Dessa forma, as oportunidades diante do processo legislativo, que caminhará após a recomposição de mandatos dos parlamentares nas eleições de outubro de 2018, apresentam-se firmes para concretização. No Senado brasileiro, em geral, existe espaço qualificado a permitir atuação também contundente de uma base de representantes sensibilizados com o equilíbrio de interesses, atenta ao envolvimento

20 As principais operadoras Oi, Vivo e Tim tem assumido o comportamento característico de mercados oligopolizados, recorrendo a grandes operações societárias e corporativas, planos de reestruturação, troca de ações com investidores e empresas estrangeiras e outros acordos financeiros que são tecnicamente projetados para racionalizar as operações e expandir as unidades de negócios no Brasil. 
da sociedade civil e da academia em decisões técnicas a respeito da Internet no Brasil.

Revistar a LGT, mais uma vez, é permitir a reconstrução de marco regulatório destinado a impulsionar a universalização da internet por serviços de banda larga de qualidade. A reforma ainda pode assegurar que princípios instrumentais definam o campo normativo pró-universalização da internet, alcançando o setor a ser regulado (a exemplo da universalidade, acessibilidade, continuidade, eficiência e garantia de proteção de direitos dos usuários consumidores), em sentido consistente com o diálogo constitucional e com o Marco Civil da Internet.

\section{AMBIENTES PARA A INCLUSÃO DIGITAL NO BRASIL: RECOMENDAÇÕES e CONCLUSOES}

Por fim, seria relevante discutir possíveis recomendações ao modelo vislumbrado para o segmento da internet no Brasil, especificamente no que concerne à universalização dos serviços de provimento de acesso por banda larga e sua essencialidade.

Em vista de outras experiências em escala global, o Estado brasileiro não pode se afastar da atuação regulatória em função da estrutura das redes informáticas e comunicacionais e da dinâmica da atividade econômica implicada no acesso à internet. Mais uma vez, repita-se, não há argumento liberal econômico em pleno século XXI que tenha como suportar modelos de desregulamentação e leis mais frouxas para mercado, particularmente quando o 'mar de liberdade' é tomado por ambientes de captura, lobbies não transparentes e processos corruptores, estruturas oligopolísticas de mercado e distorções no sistema prevalente de tributação e distribuição de renda. Sem regulação, por exemplo, empresas de provimento de conexão à Internet não teriam quaisquer travas para comercializar planos com franquias reduzidas associados a práticas de zero-rating, em violação manifesta do princípio de neutralidade de rede, estabelecido pelos Arts. $3^{\circ}$ e $9^{\circ}$ do Marco Civil da Internet. Sem defesa das relações de consumo, usuários assinantes de pacotes de dados teriam dificuldades de pleitear resilição de contratos por descumprimento das 
operadoras, má qualidade na prestação do serviço e propaganda enganosa, padrão que tem sido comum no provimento de acesso à internet.

Para reverter e reduzir externalidades da elevada concentração nos segmentos de telefonia e que também afetam o provimento de banda larga, distintos modelos regulatórios na União Europeia, por exemplo, dependeram fortemente, e continuam a depender, da presença das autoridades dos Estados Membros e dos órgãos comunitários. Esses modelos objetivam assegurar níveis de concorrência e inovação nos mercados, ao mesmo tempo em que oferecem garantias à população de usuários de opções competitivas de serviços de acesso, mediante tarifas e preços razoáveis, em qualidade superior de tráfego e velocidade média ${ }^{21}$. A primeira lição a ser tirada para os debates no Congresso Nacional é a urgência de considerar o serviço de provimento de banda larga como serviço essencial, submetido a regime de investimentos públicos e privados, regulado e a ser expandido.

A oportunidade de reforma da LGT também abre espaço, a meu ver, para a integração normativa com o Marco Civil e políticas industriais e tecnológicas orientadas pela inovação e incremento das bases educacionais e científicas em escala nacional. A partir da ampliação do acesso à internet por banda larga fixa e móvel de qualidade, o Brasil também teria condições de impulsionar investimentos em setores de economia digital (para além do problemático plano do Executivo no caso da Estratégia de Transformação Digital|22), além de recuperar objetivos do Programa de Inclusão Digital. Iniciado em 2003, como parte da Lei n. 11.012, de 21 dezembro de 2004, O Programa articula objetivos de inclusão por educação e acesso a computadores e implementação de políticas sociais e econômicas, como expansão de atendimento, com qualidade, e garantia de tratamento prioritário para aqueles segmentos tradicionalmente excluídos dos benefícios das ações públicas e discriminados por preconceitos sociais.

\footnotetext{
${ }^{21}$ Apenas a título comparativo, a velocidade média de banda fixa na Alemanha, Reino Unido e Espanha seria, respectivamente de 41,2 Mbps, 50,6 Mbps e 61,02Mbps (status SpeedTest Report 2018: http://www.speedtest.net/reports/). No Brasil, ela é de 24,7 Mbps, ao lado do México, em 20,5 Mbps, outro país também severamente afetado pela elevada concentração econômica no setor e fragilidades no ambiente regulatório.

${ }^{22}$ Sobre isso, já escrevi brevemente no artigo "O Brasil na contramão da agenda global da inclusão digital: perspectivas e retrocessos de um projeto negligenciado", de 16 de setembro de 2018. Disponível em: <http://irisbh.com.br>.
} 
Especificamente em relação à subsistência e viabilidade, o Programa brasileiro de Inclusão Digital e estratégias solidas de transformação digital endereçadas às indústrias de tecnologia da informação e internet encontram espaço para apoio por fundos setoriais já existentes. Dente eles, destaca-se o Fundo de Universalização dos Serviços de Telecomunicações - Fust ${ }^{23}$. Da mesma forma, o financiamento pode ser viabilizado pela reversão de multas aplicadas pelas autoridades brasileiras como decorrência de práticas infrativas levadas a cabo pelas operadoras, todos formalizados em termos de ajuste de conduta no âmbito de processos administrativos e judiciais. Esses temas caminhavam em discussão com o Projeto de Lei da Câmara No. 5319 de 2016, objetivando acrescenta dispositivo à LGT para considerar essencial o serviço de acesso à internet em banda larga ${ }^{24}$.

Outra alternativa para financiamento seria a conversão automática e obrigatória dos valores de multas, aplicadas em conexão a esses procedimentos, para maiores investimentos em redes de fibra ótica nas regiões consideradas prioritárias, como Norte, Nordeste e Centro Oeste (com o que as disparidades de penetração de internet por banda larga poderiam ser corrigidas), além de incentivos para operações efetivas de satélite SGDC, de tecnologia $5 \mathrm{G}$ e de projetos de cidade inteligente, concentrados no uso intensivo de novas tecnologias para planejamento urbano, mobilidade e acesso à moradia.

As soluções acima descritas retomam a relevância de política normativa em torno da consideração do provimento de acesso à internet como serviço essencial ou de utilidade pública, tema deliberadamente retirado do processo reformador no PL n. 79/2016. Isso significa que a articulação legislativa para a reforma da LGT, no tempo que segue, deve assegurar o pleito público preponderante em torno da

${ }^{23}$ O FUST arrecada cerca de $\mathrm{R} \$ 4$ bilhões por ano das empresas de telecomunicações, receita gerada a partir das faturas pagas pelo consumidor final no Brasil. Apenas $1 \%$ dos valores investidos desde 2001 tem sido, de fato, aplicado em universalização. Instituído pela Lei oํ 9.998, de 17 de agosto de 2000 , o Fundo tem como objetivo de proporcionar recursos destinados ao cumprimento das obrigações de universalização de serviços de telecomunicações. Sua execução se dá pelo MCTIC, a quem cabe formular as políticas, as diretrizes gerais e as prioridades que orientam as aplicações, bem como definir os programas, projetos e atividades financiados com recursos ali existentes.

24 Texto integral em

$<$ www.camara.gov.br/proposicoesWeb/fichadetramitacao?idProposicao=2084820> 
universalização do acesso à internet. Insistir em modelo ultrapassado seria compactuar com o retrocesso.

Como observado anteriormente, é o pleito de universalização que sustenta a relação indissociável entre políticas de inclusão digital e de transformação digital no Brasil, e ele considera os fatores de disponibilidade, acessibilidade e distribuição regionalmente equitativa da rede mundial de computadores como centrais para desenvolvimento daquelas duas frentes da agenda digital global. O caso brasileiro, desde o Marco Civil, ainda é digno de referência, e deve ser explorado adiante, particularmente pelo interesse público na promoção de direitos fundamentais associados ao espaço transnacional da informação e tecnologia, que é representado, em todos sentidos, pela internet como a conhecemos.

\section{REFERÊNCIAS}

AGÊNCIA BRASIL. Especialistas, empresas e governo debatem Lei Geral das Teles. 08/05/2018.

Disponível em: $<$ http://agenciabrasil.ebc.com.br/politica/noticia/2018-05/senado-especialistasempresas-e-governo-debatem-lei-geral-das-teles> Acesso em 30 de dezembro de 2018.

ANASTACIO, Kimberly; SANTARÉM, Paulo; ZANATTA, Rafael. Texto de posição sobre Reforma da Lei Geral das Telecomunicações e o Projeto de Lei no 3.453/2015. Instituto Beta e Instituto Brasileiro de Defesa do Consumidor. Julho de 2016. Disponível em: <https://goo.gl/PexdHs> Acesso: 30 de dezembro de 2018.

ANATEL. Documento de Encaminhamento da Lei Geral das Telecomunicações. Brasília: Agência Nacional das Telecomunicações. 1996. Versão integral em: $<$ http://www.anatel.gov.br/Portal/verificaDocumentos/documento.asp?numeroPublica cao=331> Acesso: 30 de dezembro de 2018.

ANATEL. Bens Reversíveis. 09 de Abril de 2015. Disponível em: < www.anatel.gov.br/dados/telefonia-fixa/telefonia-fixa> Acesso: 30 de dezembro de 2018.

AZEVEDO, Antonio Junqueira. O direito pós-moderno e a codificação. In: Revista da Faculdade de Direito, Universidade de São Paulo, vol. 94, p.3-12, 1999.

CASTELLS, Manuel. A era da informação: economia, sociedade e cultura. In: A Sociedade em Rede. São Paulo: Paz e Terra, 2000. 
CÂMARA DOS DEPUTADOS. Senado Federal. Projeto de Lei da Câmara $\mathbf{n}^{\circ} \mathbf{7 9}$, de 2016. Disponível em: https://www25.senado.leg.br/web/atividade/materias/Imateria/127688. Acesso em: 30 de dezembro de 2018.

COMITÊ GESTOR DA INTERNET. TIC Domicílios 2017. Disponível em: <https://cetic.br/pesquisa/domicilios/indicadores>. Acesso: 30 de dezembro de 2018.

COUTINHO, Diogo R. Entre eficiência e equidade: a universalização das telecomunicações em países em desenvolvimento. In: Revista Direito GV, vol.1, n.2, p.137-160. 2005.

FARACO, Alexandre Ditzel. Regulação e direito concorrencial: as telecomunicações. São Paulo: Livraria Paulista, 2003.

FREEDOM HOUSE, Freedom on the Net 2018: The Rise Of Digital Authoritarianism. New York: Freedom House, 2018. Disponível em: <https://freedomhouse.org/report/freedom-net/freedom-net-2018> Accesso: 30 de dezembro de 2018.

HELENA, Maria. Câmara dos Deputados. PL 5319/2016. Disponível em: https://www.camara.leg.br/proposicoesWeb/fichadetramitacao?idProposicao=208482 0. Acesso em: 30 de dezembro de 2018

IRIS. Fake news: iniciativas legislativas não devem violar garantias fundamentais. Belo Horizonte, Instituto de Referência em Internet e Sociedade, 2018. Disponível em: <http://www.irisbh.com.br>. Acesso: 30 de dezembro de 2018.

LEAL, Sayonarae HAJE, Lara. Projetos de convergência tecnológica para as comunicações no Brasil: descompasso entre interesse público e interesse privado. Intercom - Sociedade Brasileira de Estudos Interdisciplinares da Comunicação. XXXX Congresso Brasileiro de Ciências da Comunicação. Santos. Setembro de 2007.

SUNDFELD, Carlos Ari e ARRUDA CÂMARA, Jacintho. Bens Reversíveis nas Concessões Públicas: A inviabilidade de uma teoria geral. In: Revista da Faculdade de Direito UFPR. Vol. 61, n. 2, p. 149-174, 2016.

$\mathrm{ONU}$, The promotion, protection and enjoyment of human rights on the Internet. Resolution adopted on July 4, 2016. Doc. A/HRC/32/L.20. Disponível em:<http://digitallibrary.un.org/record/845728? $\mid \mathrm{n}=\mathrm{en}>$ ).

PENA, Andre Garcia; ABDALLA JÚNIOR, Humberto; PEREIRA FILHO, José Leite. A banda larga e o cenário brasileiro das telecomunicações. In: Revista de Direito, Estado e Telecomunicações, v. 4, n. 1, p. 237-302. 2012.

PROCON, Ranking: Lista de reclamações no Procon de todo país 2018. Disponível em: < https://www.procononline.com.br/reclamacoes-no-procon/> Acesso: 30 de dezembro de 2018. 
SALOMÃO FILHO, Calixto. Regulação e desenvolvimento: novos temas. São Paulo: Malheiros Editores, 2012.

SILVEIRA, André. Para Anatel, valor dos bens reversíveis só podem ser calculados após sanção do PLC 79/2016. 2018. Teletime. Disponível em: $<$ http://teletime.com.br/08/05/2018/para-anatel-valor-dos-bens-reversiveis-so-apossancao-do-plc-79-2016/>). Acesso: 30 de dezembro de 2018.

SOUSA MELO, Paulo Roberto, e GUTIERREZ, Regina M. V. Telecomunicações PósPrivatização: Perspectivas Industriais e Tecnológicas. In: BNDES Setorial. Banco Nacional de Desenvolvimento. 2002.

TEPEDINO, Gustavo. O Código Civil, os chamados microssistemas e a Constituição: premissas para uma reforma legislativa: In: TEPEDINO, Gustavo (coord). Problemas de direito civil-constitucional. Rio de Janeiro: Renovar, 2000, p.1-16.

WIPO, Global Innovation Index 2018: Energizing the World with Innovation. Disponível em: <https://www.globalinnovationindex.org/gii-2018-report\#>. Acesso: 30 de dezembro de 2018.

WORLD BANK, World Development Report 2016: Digital Dividends - An overview. Washington, DC: International Bank for Reconstruction and Development, 2016. Disponível em: <http://www.worldbank.org/en/publication/wdr2016>. Acesso: 30 de dezembro de 2018.

POLIDO, Fabrício B.P. Direito Internacional Privado nas Fronteiras do Trabalho e Tecnologias: Ensaio e narrativas na era digital. 1.ed. Rio de Janeiro: Lumen luris, $2018 . \quad$ Disponível em: <https://ufmg.academia.edu/FabricioBertiniPasquotPolido/Books>. Acesso: 30 de dezembro de 2018.

POLIDO, Fabrício B.P. Direito internacional e sociedade global da informação: reflexões sobre o direito de acesso à internet como direito fundamental da pessoa humana. In: Revista da Faculdade de Direito da UFMG. ed.esp, 2013, p.197-252. Disponível: <https://www.direito.ufmg.br/revista/index.php/revista/issue/view/29>.

POLIDO, Fabrício B. P. O Brasil na contramão da agenda global da inclusão digital: perspectivas e retrocessos de um projeto negligenciado. Blog do IRIS. 16 de setembro de 2018. Disponível em: <http://irisbh.com.br>

CETIC, Banda Larga no Brasil: um estudo sobre a evolução do acesso e da qualidade das conexões à Internet. O Núcleo de Informação e Coordenação do Ponto BR/Cetic. São Paulo, 2018. Disponível em: <https://cetic.br/publicacoes/indice/>. Acesso: 30 de dezembro de 2018. 